\title{
PENGARUH SELF-EFFICACY DAN DUKUNGAN KELUARGA TERHADAP KEPATUHAN MENJALANI TERAPI PADA PENDERITA HIPERTENSI
}

\author{
Kurniati Prihatin', Marthilda Suprayitna' ${ }^{2}$, Baiq Ruli Fatmawati ${ }^{3}$ \\ 1,2,3 STIKes Yarsi Mataram \\ mathildasuprayitna@gmail.com
}

\begin{abstract}
ABSTRAK
Kepatuhan penderita hipertensi dalam menjalani terapi hipertensi merupakan faktor penting dalam proses pengobatan hipertensi. Proses pengobatan hipertensi dipengaruhi oleh beberapa faktor diantaranya self-efficacy dan dukungan keluarga. Penelitian ini bertujuan untuk mengetahui adanya pengaruh self efficacy dan dukungan keluarga terhadap kepatuhan menjalani terapi pada penderita hipertensi di Wilayah Kerja Puskesmas Penimbung, Desa penimbung Lombok Barat. Penelitian menggunakan deskriptif analitik dengan pendekatan cross-sectional. Penelitian dilakukan pada 167 responden. Teknik pengambilan sampel dengan accidental sampling. Analisis data yang digunakan adalah Chi-Square. Hasil penelitian menunjukkan bahwa ada pengaruh antara self-efficacy terhadap kepatuhan terapi penderita hipertensi ( $p$-value: 0,000) serta adanya pengaruh antara dukungan keluarga terhadap kepatuhan terapi penderita hipertensi (p-value: 0,000). Keyakinan penderita akan kemampuannya menjalankan terapi hipertensi merupakan hal yang sangat memengaruhi kepatuhan terapi pada penderita hipertensi dan ketika keyakinan didukung oleh keluarga maka akan semakin meningkatkan keyakinan penderita dalam menjalani terapi hipertensi. Penelitian ini diharapkan dapat menginspirasi kepada pemberi pelayanan kesehatan untuk meningkatkan pengetahuan pasien dan melibatkan keluarga dalam perawatan penderita hipertensi.
\end{abstract}

Kata kunci : dukungan keluarga, hipertensi,kepatuhan terapi, self-efficacy

\begin{abstract}
Patient adherence in carrying out therapy is an essential thing in handling hypertension sufferers. Therapy adherence requires a strong belief in the patient is undergoing therapy. Hypertension therapy is long-term and even lifelong and sustainable at home, so not only the patient's involvement is a concern but social support, especially family, is also very important in increasing therapy adherence. This study aims to determine the effect of self-efficacy and family support on adherence to hypertension patients in the Work Area of the Penimbung Health Center, West Lombok Penimbung Village. It was using Analytical Descriptive with a Cross-Sectional approach located in the Work Area of the Penimbung Health Center, West Lombok Penimbung Village with a total sample of 167 respondents. The sampling technique is by accidental sampling. The data analysis used is Chi-Square. There is a relationship between self-efficacy and family support on therapeutic adherence to hypertension sufferers (p-value: 0.000). The patient's belief in his ability to carry out hypertension therapy is a significant influencing adherence to therapy in hypertensive sufferers. Furthermore, when the family supports the belief, it will further increase the patient's confidence in undergoing hypertension therapy. It hoped that with this research, health service providers could increase patient knowledge and involve families in the care of hypertension sufferers.
\end{abstract}

Keywords: family support, hypertension, self-efficacy, therapy adherence 


\section{PENDAHULUAN}

Penyakit hipertensi merupakan salah satu faktor risiko utama yang mengarah kepada penyakit kardiovaskuler seperti serangan jantung, gagal jantung, strok dan penyakit ginjal yang disinyalir pada tahun 2016 penyakit-penyakit tersebut merupakan penyebab kematian utama di dunia (World Health Organization, 2018).

Prevalensi hipertensi tertinggi adalah di Afrika, yaitu $46 \%$ dari orang dewasa berusia di atas 25 tahun. Adapun prevalensi terendah yaitu 35\% di Amerika. Kaldara et al, (2015) mengatakan bahwa prevalensi hipertensi di dunia terus meningkat, diprediksi pada tahun 2025 angka akan mencapai 1.56 miliar orang dengan perkiraan angka kematian akibat hipertensi dan komplikasi sebanyak 9,4 juta orang.

Data prevalensi hipertensi di Indonesia menurut Kementerian Kesehatan Republik Indonesia (Kemenkes RI, 2019) sebanyak 65.048.110 jiwa (34,1\%), sedangkan menurut data dari Riset Kesehatan Dasar di Indonesia terdapat peningkatan prevalensi penderita hipertensi dari tahun 2013-2018. Hasil pengukuran pada tahun 2013 prevalensi hipertensi berdasarkan penduduk usia lebih dari 18 tahun sebesar 25,8\% dan terjadi peningkatan pada tahun 2018 menjadi $34,1 \%$. Adapun menurut Dinas Kesehatan Nusa Tenggara Barat (2018) angka kejadian hipertensi terus mengalami peningkatan pada tahun 2018 sebanyak 221.095 jiwa.

Hasil pengukuran tekanan darah penduduk yang berusia lebih dari 18 tahun menurut jenis kelamin dan kabupaten di Provinsi Nusa Tenggara Barat (NTB) tahun 2018, persentase penderita hipertensi di Lombok Barat sebesar (47, 64\%) dan merupakan yang tertinggi di NTB (Dinkes NTB, 2018). Adapun jumlah penderita hipertensi di Wilayah Kerja Puskesmas Penimbung, Desa Penimbung Lombok Barat pada tahun 2019 sebanyak 287 kasus.

Hipertensi merupakan salah satu penyakit kronis yang memerlukan biaya tinggi dalam pengelolaannya, program terapi jangka panjang bahkan seumur hidup dan kelanjutan perawatan di rumah secara terus-menerus. Kepatuhan dan kerjasama dari penderita hipertensi sangat dibutuhkan dalam program terapi seperti pengobatan hipertensi, pola diet, melakukan aktivitas dan olah raga guna menghindari peningkatan kejadian kekambuhan pada penderita hipertensi. Oleh karena itu, pada penatalaksanaan penderita hipertensi, kepatuhan penderita pada terapi sangat penting diperhatikan agar penatalaksanaan hipertensi dapat berhasil. Pengelolaan penyakit jangka panjang dapat menimbulkan kejenuhan dan frustasi pada penderitanya. Dampak dari pengelolaan penyakit yang buruk dapat berakibat pada seluruh aspek kehidupan baik fisik, psikologis, sosial maupun ekonomi. Beberapa penelitian telah mengidentifikasi pentingnya aspek self care management pada pasien penyakit kronis. mencegah dan meminimalkan risiko komplikasi (Ridillah, 2018).

Salah satu strategi utama yang dapat dilakukan untuk meningkatkan kepatuhan yaitu dari segi penderita sendiri dengan meningkatkan self-efficacy Seseorang yang memiliki keyakinan kuat terhadap dirinya sendiri dan berpegang teguh terhadap keyakinannya akan memiliki perilaku lebih baik terhadap anjuran dan larangan pengobatan (Rizka, 2012).

Self efficacy merupakan keyakinan seseorang yang menjadi acuan penting dalam bersikap patuh. Pengobatan yang kompleks akan mampu dilaksakan dengan baik jika seseorang mampu memiliki self-efficacy yang kuat (Bandura, 2010). Dukungan sosial sangat dibutuhkan dalam menjaga kestabilan kepatuhan terapi seseorang. Hal ini diperlukan untuk meminimalkan efek negatif stressor seperti depresi kesendirian, beban penyakit, dan penerimaan terhadap penyakit.

Lingkungan sosial yang paling utama 
pada seorang individu yaitu keluarga. Sikap, tindakan dan penerimaan merupakan suatu proses hubungan di dalam dukungan keluarga yang dapat bersumber dari dukungan internal (suami, istri, dan anak) atau dukungan eksternal. Berdasarkan hasil survei pendahuluan yang dilakukan oleh peneliti pada dua belas orang penderita yang mengalami penyakit hipertensi di Puskesmas Penimbung, Desa Penimbung Lombok Barat, didapatkan hasil bahwa tujuh dari dua belas orang yang menderita hipertensi datang ke pelayanan ketika telah merasakan keluhan yang cukup berat dan tidak kontrol sesuai jadwal yang diberikan. Dari tujuh penderita tersebut rata-rata memiliki alasan yang sama yaitu kesibukan keluarga (anak) yang harus mengantar penderita datang ke pelayanan. Adapun tiga dari dua belas penderita lainnya mengatakan bahwa dirinya tidak datang tepat waktu sesuai jadwal yang dianjurkan dengan alasan bahwa dirinya datang ke pelayanan jika merasakan keluhan saja. Terkadang penderita hipertensi datang dengan kondisi obat yang harus dikonsumsi telah beberapa lama tidak dikonsumsi oleh penderita sehingga keluhan dari penyakit kembali dirasakan oleh penderita. Dari dua belas orang hanya dua orang penderita hipertensi yang rutin melakukan kontrol sesuai waktu yang disarankan tenaga kesehatan.

Berdasarkan fenomena tersebut peneliti merasa penting untuk menggali pengaruh self-efficacy dan dukungan keluarga terhadap kepatuhan terapi pada pasien hipertensi Wilayah Kerja Puskesmas Penimbung, Desa Penimbung Lombok Barat. Penelitian ini diharapkan dapat mengetahui adanya pengaruh self-efficacy dan dukungan keluarga terhadap kepatuhan menjalani terapi pada penderita hipertensi di Wilayah Kerja Puskesmas Penimbung, Desa Penimbung Lombok Barat.

\section{METODOLOGI}

Desain penelitian ini menggunakan deskriptif analitik dengan pendekatan crosssectional. Populasi penelitian adalah penderita hipertensi di Wilayah Kerja Puskesmas Penimbung, Desa Penimbung Lombok Barat sejumlah 287 orang. Pengambilan sampel dilakukan dengan teknik accidental sampling diperoleh sampel sebanyak 167 sesuai dengan kriteria inklusi yaitu merupakan penderita hipertensi primer di Wilayah Kerja Puskesmas Penimbung, Desa Penimbung Lombok Barat, dapat membaca dan menulis, dan bersedia menjadi responden.

Variabel independen penelitian ini adalah self-efficacy dan dukungan keluarga sedangkan variabel dependen adalah kepatuhan terapi. Pengambilan data dilakukan menggunakan kuesioner self-efficacy, dukungan keluarga dan kepatuhan. Ketiga kuesioner tersebut dilakukan secara bersamaan pada satu waktu.

Analisis yang digunakan dalam penelitian ini yaitu menggunakan uji statistik Chi-Square untuk mengetahui pengaruh self-efficacy dan dukungan keluarga terhadap kepatuhan terapi pada penderita hipertensi di Wilayah Kerja Puskesmas Penimbung, Desa Penimbung Lombok Barat.

\section{HASIL}

1. Karakteristik responden

Tabel 1. Karakteristik Responden Meliputi Umur, Jenis Kelamin, Pendidikan dan Lama Menderita pada Pasien Hipertensi Tahun 2019

$$
(\mathrm{n}=167)
$$

\begin{tabular}{lcc}
\hline \multicolumn{1}{c}{$\begin{array}{c}\text { Karakteristik } \\
\text { Variabel }\end{array}$} & n & \% \\
\hline Umur & & \\
$\leq 40$ tahun & 0 & 0 \\
$41-60$ tahun & 86 & 51,5 \\
$>60$ tahun & 81 & 48,5 \\
\hline
\end{tabular}




\begin{tabular}{lcc}
\hline \multicolumn{1}{c}{$\begin{array}{c}\text { Karakteristik } \\
\text { Variabel }\end{array}$} & n & \% \\
\hline Jenis Kelamin & 125 & 74,9 \\
Laki-laki & 42 & 25,1 \\
Perempuan & & \\
Pendidikan & 0 & 0 \\
Tidak Sekolah & 11 & 6,6 \\
SD & 47 & 28,1 \\
SMP & 70 & 41,9 \\
SMA & 39 & 23,4 \\
PT & & \\
\hline
\end{tabular}

\begin{tabular}{lcc}
\hline \multicolumn{1}{c}{$\begin{array}{c}\text { Karakteristik } \\
\text { Variabel }\end{array}$} & n & \% \\
\hline Lama Menderita & & \\
$\leq 1$ tahun & 89 & 53,3 \\
$>1$ tahun & 78 & 46,7 \\
\hline
\end{tabular}

Karakteristik responden berdasarkan umur didapatkan umur dominan dalam rentang 40-60 tahun 51,5\%, sedangkan jenis kelamin dominan adalah laki-laki $74,9 \%$. Responden lebih banyak dengan tingkat pendidikan SMA $41,9 \%$ dan responden dengan lama menderita kurang dari 1 tahun yaitu sebanyak 53,3\%.

2. Hasil Analisis Penelitian

Tabel 2. Pengaruh Self-efficacy dan Dukungan Keluarga terhadap Kepatuhan Penderita Hipertensi Tahun 2019

\begin{tabular}{|c|c|c|c|c|c|c|c|}
\hline \multicolumn{8}{|c|}{$(n=167)$} \\
\hline & \multicolumn{6}{|c|}{ Kepatuhan Terapi } & \multirow{3}{*}{ p-value } \\
\hline & \multicolumn{2}{|c|}{ Patuh } & \multicolumn{2}{|c|}{ Tidak Patuh } & \multicolumn{2}{|c|}{ Total } & \\
\hline & $\mathbf{n}$ & $\%$ & $\mathbf{n}$ & $\%$ & $\mathbf{n}$ & $\%$ & \\
\hline \multicolumn{8}{|l|}{ Self efficacy } \\
\hline Yakin & 77 & 91,7 & 7 & 8,3 & 84 & 100 & 0,000 \\
\hline Tidak Yakin & 9 & 10,8 & 74 & 89,2 & 83 & 100 & \\
\hline Total & 86 & 51,5 & 81 & 48,5 & 167 & 100 & \\
\hline \multicolumn{8}{|l|}{ Dukungan Keluarga } \\
\hline Ada dukungan & 80 & 95,2 & 4 & 4,8 & 84 & 100 & 0,000 \\
\hline Tidak ada dukungan & 6 & 7,2 & 77 & 92,8 & 83 & 100 & \\
\hline Total & 86 & 51,5 & 81 & 48,5 & 167 & 100 & \\
\hline
\end{tabular}

Hasil analisis antara self-efficacy dengan kepatuhan terapi penderita hipertensi diperoleh nilai $p$-value $<0,05$, sehingga diperoleh hasil terdapat hubungan yang bermakna antara self-efficacy terhadap kepatuhan pada penderita hipertensi. Selanjutnya hasil analisis antara dukungan keluarga dengan kepatuhan terapi penderita hipertensi yaitu didapatkan $p$-value $<0,05$ sehingga didapatkan hasil terdapat hubungan yang bermakna antara dukungan keluarga dengan kepatuhan terapi pada penderita hipertensi. Pada variabel self-efficacy didapatkan
77 orang $(91,7 \%)$ yakin terhadap kemampuannya dapat patuh terhadap terapi hipertensi dengan hasil uji statistik didapatkan nilai $p$-value sebesar 0,000 . Adapun pada variabel dukungan keluarga didapatkan hasil sebanyak 80 orang $(95,2 \%)$ memiliki dukungan keluarga dan mampu patuh terhadap terapi dengan hasil uji statistik didapatkan nilai $p$-value $=0,000$.

\section{PEMBAHASAN}

Analisis pengaruh self-efficacy terhadap kepatuhan terapi penderita hipertensi di Wilayah 
Kerja Puskesmas Penimbung, Desa Penimbung Lombok Barat berdasarkan hasil penelitian dinyatakan bahwa terdapat hubungan antara self- efficacy dengan kepatuhan pada responden hipertensi di Wilayah Kerja Puskesmas Penimbung, Desa Penimbung Lombok Barat dengan nilai $\mathrm{p}=0,000$. Didapatkan jumlah responden lebih banyak yang memiliki keyakinan (self-efficacy) patuh terhadap terapi hipertensi. Hal ini disebabkan oleh banyaknya diantara responden yang mampu beradaptasi dengan self-efficacy dalam menjalani terapi hipertensi dengan meningkatkan pengetahuannya atau mengubah perilakunya. Hal ini juga didukung dengan banyaknya responden yang mendapat dukungan dari anggota keluarga dalam menjalani terapi hipertensi. Selain itu, hal ini disebabkan oleh penderita banyak mendapatkan pengetahuan terkait penyakit tidak hanya dari pemberi pelayanan kesehatan tetapi juga banyak dari media informasi lainnya seperti media cetak ataupun elektronik, yang mengindikasikan pengetahuan menjadi dasar individu untuk menentukan perilakunya(Katch, 2010).

Hal ini didukung oleh penelitian yang dilakukan oleh Ariesti \& Pradikatama (2018) yang menyatakan bahwa pada penderita yang memiliki self-efficacy yang kuat akan cenderung patuh terhadap terapi yang dijalaninya sehingga mampu mengambil keputusan yang tepat dalam menentukan tindakan. Seseorang yang memiliki keyakinan kuat terhadap dirinya sendiri dan berpegang teguh terhadap keyakinannya akan memiliki perilaku lebih baik terhadap anjuran dan larangan pengobatan.

a. Analisis Dukungan Keluarga Terhadap Kepatuhan Terapi Penderita Hipertensi di Wilayah Kerja Puskesmas Penimbung, Desa Penimbung Lombok Barat

Dari hasil penelitian didapatkan bahwa terdapat hubungan antara dukungan keluarga dengan kepatuhan pada responden hipertensi di Wilayah kerja Penimbung, Lombok Barat dengan nilai $\mathrm{p}=0,000$. Hal ini disebabkan oleh karakteristik usia penderita hipertensi yang rata-rata pada usia dewasa atau produktif sampai usia lansia dengan rata-rata sudah berkeluarga dan dikarenakan oleh bentuk keluarga lebih banyak extended family yaitu satu rumah dihuni oleh beberapa anggota keluarga serta kepercayaan di daerah Penimbung yang lebih mengutamakan kesejahteraan anggota keluarga yang lebih tua. Hal ini memungkinkan penderita mendapatkan dukungan dari anggota keluarganya berupa dukungan informasional, dukungan emosional, dukungan instrumental dan dukungan penghargaan.

Dengan dukungan dari keluarga maka penderitahipertensidapattermotivasidanyakin akan kemampuan dirinya dalam melaksanakan dan mematuhi terapi hipertensi. Individu yang mendapat perhatian dan penghiburan ataupun pertolongan dari keluarganya cenderung lebih mudah mengikuti nasehat medis. Hal ini sejalan dengan penelitian yang dilakukan oleh (Pratiwi, 2012) yang mengatakan bahwa dukungan keluarga sangat berkontribusi pada kepatuhan pasien dalam mematuhi terapi yang sedang dijalani.

\section{SIMPULAN DAN SARAN}

Berdasarkan hasil penelitian, maka dapat ditarik kesimpulan: 1) Penderita hipertensi di Wilayah Kerja Puskesmas Penimbung, Desa Penimbung Lombok Barat lebih banyak yang memiliki self-efficacy akan kemampuannya dalam menjalani terapi hipertensi. 2) Penderita hipertensi di Wilayah Kerja Puskesmas Penimbung, Desa Penimbung Lombok Barat lebih banyak yang mendapat dukungan keluarga dalam menjalani terapi Wilayah Kerja Puskesmas 
Penimbung, Desa Penimbung Lombok Barat. 3) Penderita hipertensi di Wilayah Kerja Puskesmas Penimbung, Desa Penimbung Lombok Barat lebih banyak yang patuh terhadap terapi. 4) Ada pengaruh yang bermakna antara self-efficacy dan kepatuhan pada penderita hipertensi. 5) Terdapat pengaruh bermakna antara dukungan keluarga dan kepatuhan pada penderita hipertensi.

Dari hasil penelitian ini diharapkan dapat dilakukan pengembangan antara lain: pengembangan self-efficacy sebagai konsep sentral dari Health Promotion Model (HPM) pada penderita dengan kasus penyakit kronis khususnya pada penderita hipertensi untuk menumbuhkan komitmen penderita dalam melakukan upaya-upaya promosi kesehatan.

Perawat harus mampu memotivasi penderita untuk dapat meyakinkan dirinya bahwa penderita mampu melaksanakan terapi yang dianjurkan, membantu mengatasi kecemasan dan membantu mempersiapkan lingkungan sosial penderita. Selain itu, petugas diharapkan mampu meningkatkan pengetahuan keluarga agar dapat memotivasi keluarga untuk memberikan dukungan secara utuh antara lain berupa dukungan emosional, dukungan instrumental, dukungan informasional, dan dukungan penghargaan. Hal tersebut disebabkan oleh hipertensi merupakan penyakit yang membutuhkan kepatuhan yang konsisten dalam menjalani terapinya.

\section{DAFTAR PUSTAKA}

Ariesti, E., \& Pradikatama, Y. (2018). Hubungan Self-Efficacy Dengan Tingkat Kepatuhan Kota Malang. Jurnal Keperawatan Malang, 3, 39-44.

Bandura, A (2010). Self-efficacy. The Corsini encyclopedia of psychology, Wiley
Online Library

Dinkes NTB. (2018). Profil Kesehatan NTB 2018. Journal of Chemical Information and Modeling, 53(9), 1689-1699.

Kaldara, E., Sanoudou, D., Adamopoulos, S., \& Nanas, J. N. (2015). Outpatient management of chronic heart failure. Expert Opinion on Pharmacotherapy, 16(1), 17-41. https://doi.org/10.1517/14 656566.2015 .978286

Katch, H. (2010). The role of self-efficacy in cardiovascular disease self-management: a review of effective programs. Patient Intelligence, 33. https://doi.org/10.2147/ pi.s12624

Kemenkes RI. (2019). Profil Kesehatan Indonesia 2018 [Indonesia Health Profile 2018]. http://www.depkes.go.id/resources/ download/pusdatin/profil-kesehatanindonesia/Data-dan-Informasi_ProfilKesehatan-Indonesia-2018.pdf

Pratiwi, E. Y. (2012). Dukungan Keluarga Terhadap Kepatuhan Menjalankan Program Terapi pada Pasien Terapi Rumatan Metadon. In Developmental and Clinical Psychology (Vol. 1, Issue 1).

Ridillah Vani J., D. (2018). Volume 5 | Nomor 2 | Desember 2018. In Jurnal Keperawatan (Vol. 5, Issue 6).

Rizka, R. (2012). Hubungan Self-Efficacy Dengan Treatment Adherence Pada Penderita Hipertensi RSI Siti Hajar. http://digilib.uinsby.ac.id/9967/

World Health Organization. (2018). Guidelines on second-and third-line medicines and type of insulin for the control of blood glucose levels in non-pregnant adults with diabetes mellitus. 